\title{
Assessment of potential human health risks in aquatic products based on the heavy metal hazard decision tree
}

\author{
Hao-Hsiang Ku ${ }^{1,2}$, Pinpin Lin ${ }^{3}$ and Min-Pei Ling ${ }^{2^{*}}$ (1)
}

From International Conference on Biomedical Engineering Innovation 2019 Kaohsiung, Taiwan. 15-19 November 2019

\author{
${ }^{*}$ Correspondence: \\ mpling@email.ntou.edu.tw \\ 2 Department of Food \\ Science, National Taiwan \\ Ocean University, Keelung \\ City 20224, Taiwan \\ Full list of author information \\ is available at the end of the \\ article
}

\begin{abstract}
Background: Naturally existing and human-produced heavy metals are released into the environment and cannot be completely decomposed by microorganisms, but they continue to accumulate in water and sediments, causing organisms to be exposed to heavy metals.

Results: This study designs and proposes heavy metal hazard decision trees for aquatic products, which are divided into seven categories including pelagic fishes, inshore fishes, other fishes, crustaceans, shellfish, cephalopods, and algae. Based on these classifications, representative fresh and processed seafood products are at the root of the heavy metal hazard decision trees. This study uses 2,107 cases of eating 556 cooked fresh or processed seafood product samples. The constructions of the proposed decision trees consist of 12 heavy metals, which include inorganic arsenic (iAs), cadmium (Cd), cobalt (Co), chromium (Cr), copper (Cu), iron (Fe), manganese $(\mathrm{Mn})$, nickel (Ni), lead (Pb), strontium ( $\mathrm{Sr}$ ), thallium (TI), and zinc ( $\mathrm{Zn})$. The heavy metal concentrations in cooked fresh and processed seafood product samples are subjected to a food safety risk assessment.
\end{abstract}

Conclusions: The results indicate the relationships among the seven categories of aquatic products, the relationships among 12 heavy metals in aquatic products, and the relationships among potential human health risks. Finally, the proposed heavy metal hazard decision trees for aquatic products can be used as a reference model for researchers and engineers.

Keywords: Decision tree, Heavy metal, Potential human health risk, Food safety risk assessment author(s) and the source, provide a link to the Creative Commons licence, and indicate if changes were made. The images or other third party material in this article are included in the article's Creative Commons licence, unless indicated otherwise in a credit line to the material. If material is not included in the article's Creative Commons licence and your intended use is not permitted by statutory regulation or exceeds the permitted use, you will need to obtain permission directly from the copyright holder. To view a copy of this licence, visit http:// creativecommons.org/licenses/by/4.0/. The Creative Commons Public Domain Dedication waiver (http://creativecommons.org/publi cdomain/zero/1.0/) applies to the data made available in this article, unless otherwise stated in a credit line to the data. 


\section{Background}

Taiwan is surrounded by the sea, with different ocean currents flowing and meeting one another, so it has abundant fish and aquatic resources. A past study showed that the people living in Taiwan consume an average of $24.62 \mathrm{~kg}$ of aquatic products each year, which is more than double the average annual consumption of $12.87 \mathrm{~kg}$ by the global population [1]. In Taiwan, people can easily buy seven categories of aquatic products at fish markets or supermarkets in counties or cities. This means that aquatic products have significant importance in the daily diet of the people in Taiwan. In recent decades, heavy metal pollutions in the environment and food have been considered a global problem [2,3]. Naturally existing and human-produced heavy metals are released into the environment and cannot be completely decomposed by microorganisms, but they continue to accumulate in water and sediments, causing organisms to be exposed to heavy metals [4-6]. Aquatic organisms can be exposed to heavy metals in multiple ways, such as through functional groups on biofilms and heavy metal bonding, gill filtration, and ingestion. When the human body ingests aquatic products, the product passes through the food chain, and the heavy metals in the product are accumulated in the bodies of human beings [7, 8]. The excessive intake of heavy metals may cause serious health problems in people. The health problems arising from different heavy metals in the body vary according to the different types of metals, exposure time, and exposure dose $[9,10]$. Therefore, it is necessary to assess the potential health risks related to heavy metals exposure in humans resulting from the intake of aquatic products.

The metal elements and inorganic arsenic (iAs) levels in fish were measured by the Core Chemical Analysis Laboratory, National Institute of Environmental Health Science, National Health Research Institutes (NIEHS, NHRI), Taiwan. For metal elements, the fish samples were digested in nitric acid with microwave and analyzed by an inductively coupled plasma-mass spectrometer. For iAs, the fish samples were extracted in nitric acid with sonication and analyzed by an inductively coupled plasma-mass spectrometer.

The estimation models are based on the Hazard Quotient (HQ) and target cancer risk of the United States Environmental Protection Agency (USEPA). These models are used to evaluate the potential health risks related to heavy metals exposure in humans through the ingestion of aquatic products $[5,11,12]$. Risk assessments consist of hazard identification, dose-response assessment, exposure assessment, and risk characterization. Hence, this study discusses the relationship between risk assessments and maximum intakes.

(1) Risk assessment. To assess the risk of people's exposure to heavy metals due to the ingestion of aquatic products in Taiwan [1]. This study integrates exposure analysis and dose-response results to compute and evaluate the Estimated Daily Intake (EDI), the Hazard Quotient (HQ), and the target cancer risk, which depend on the concentrations of heavy metals in seven categories of aquatic products. The aquatic products in this study are defined as those that people can easily buy at fish markets or supermarkets in counties or cities in Taiwan.

(2) Maximum intake. After evaluating the risk assessment, this study computes the Acceptable Daily Intake (ADI) and examines the relationships among seven catego- 
ries of aquatic products, the relationships among 12 heavy metals in aquatic products, and the relationships among potential human health risks $[8,13]$.

Regarding the aforementioned issues, this study designs and proposes heavy metal hazard decision trees for aquatic products, which are divided into seven categories, and examines the relationships among the seven categories of aquatic products, the relationships among 12 heavy metals in aquatic products, and the relationships among potential human health risks. The study indicates the risk assessments and maximum intakes of ADI.

In recent years, increasingly different aquatic products, such as large fishes, farmed fishes, algae, shellfish, crustaceans, cephalopods, and seafood products, have been investigated and researched to determine the concentrations of heavy metals in them [14-16].

Olmedo et al. discussed how levels of mercury $(\mathrm{Hg})$, cadmium $(\mathrm{Cd})$, lead $(\mathrm{Pb})$, tin $(\mathrm{Sn})$, and arsenic (As) have been found in fresh, canned, and frozen fishes and shellfish products and compared the levels with the maximum levels [17]. The authors surveyed a total of 485 samples of the 43 most frequently consumed fish and shellfish species in Andalusia to analyze their toxic elements content, including $\mathrm{Hg}, \mathrm{Cd}, \mathrm{Pb}, \mathrm{Sn}$, and As. The study recommended the provisional tolerable weekly intake (PTWI) or the benchmark dose lower confidence limit (BMDL) for a certain toxic effect. Results indicated that (1) there were high concentrations of $\mathrm{Hg}$ in predatory fish, (2) the $\mathrm{Cd}$ concentration in shellfish was higher than that in fish, (3) the $\mathrm{Pb}$ concentration in fishes other than frozen soles was almost negligible, (4) the Sn concentration in canned aquatic products was far below the limit standard value, and (5) fresh and frozen shrimps accumulated higher As concentrations than other species.

Qin et al. surveyed the concentrations of 28 trace elements, including lithium (Li), vanadium $(\mathrm{V})$, chromium $(\mathrm{Cr})$, manganese $(\mathrm{Mn})$, iron $(\mathrm{Fe})$, nickel $(\mathrm{Ni})$, copper $(\mathrm{Cu})$, molybdenum (Mo), zinc $(\mathrm{Zn})$, selenium $(\mathrm{Se})$, strontium $(\mathrm{Sr})$, cobalt $(\mathrm{Co})$, aluminum (Al), titanium (Ti), As, Cd, antimony (Sb), barium (Ba), $\mathrm{Hg}, \mathrm{Pb}$, uranium (U), silver (Ag), beryllium (Be), thallium ( $\mathrm{Tl}$ ), gallium $(\mathrm{Ga})$, tellurium $(\mathrm{Te}), \mathrm{Sn}$, and thulium $(\mathrm{Tm})$, in three farmed cyprinid fish species from Northeast China [18]. Because the detection rates of $\mathrm{Co}, \mathrm{Be}, \mathrm{Ga}, \mathrm{Ag}, \mathrm{Sn}, \mathrm{Te}, \mathrm{Tm}$, and $\mathrm{Tl}$ were less than $50 \%$, no subsequent comparison was made. The concentrations of trace elements in the three farmed fishes from high to low were $\mathrm{Zn}(7.9 \mathrm{mg} / \mathrm{kg})>\mathrm{Fe}(6.71)>\mathrm{Al}(6.30)>\mathrm{Sr}(1.171)>\mathrm{Cu}(0.293)>\mathrm{Se}(0.243)>\mathrm{Ti}$ $(0.237)>\mathrm{Ba} \quad(0.193)>\mathrm{Pb}(0.172)>\mathrm{Mn} \quad(0.136)>\mathrm{Cr} \quad(0.121)>\mathrm{Ni} \quad(0.119)>\mathrm{As}(0.096)>\mathrm{V}$ $(0.019)>\mathrm{Mo}(0.015)>\mathrm{Hg}(0.013)>\mathrm{Li}(0.01) \approx \mathrm{Cd}(0.01) \approx \mathrm{Sb}(0.01)>\mathrm{U}(0.004)$. The results were below the limit standard set by the Chinese government: As was $0.5 \mathrm{mg} /$ $\mathrm{kg}$, $\mathrm{Hg}$ was $0.3 \mathrm{mg} / \mathrm{kg}$, Pb was $0.5 \mathrm{mg} / \mathrm{kg}$, Cd was $0.1 \mathrm{mg} / \mathrm{kg}$, Cr was $2.0 \mathrm{mg} / \mathrm{kg}$, and $\mathrm{Cu}$ was $50 \mathrm{mg} / \mathrm{kg}$. Hence, results indicated that (1) the fish samples with $0.56 \%$ As, $1.13 \%$ $\mathrm{Cd}$, and $9.04 \% \mathrm{~Pb}$ were above the maximum residue limit (MRL), (2) the hazard index and target cancer risk suggested that farmed fishes were generally safe for consumers, and (3) As, Cd, and Pb should be the most important monitored targets. The study concluded that it was safe for consumers to eat farmed fishes from Northeast China.

Santo et al. surveyed an analysis of $\mathrm{Cd}$ and $\mathrm{Pb}$ contamination in fishes (Centropomus undecimalis and Mugil brasiliensis), mussels (Mytella guyanensis) and shrimps (Penaeus brasiliensis) in the municipality of São Francisco do Conde, located in Todos os Santos 
Bay, Brazil [19]. Among the 47 samples, 11 samples had at least one metal exceeding the $\mathrm{Cd}$ and $\mathrm{Pb}$ limit standards in aquatic products established by Brazil $(\mathrm{Cd}: 1 \mu \mathrm{g} / \mathrm{g}$; Pb: $2 \mu \mathrm{g} / \mathrm{g})$. However, all fishes were within the limit standard. Hence, the study speculated that shellfish were more likely to accumulate heavy metals in the body than fishes and shrimps.

Copat et al. evaluated the concentrations of $\mathrm{As}, \mathrm{Cd}, \mathrm{Cr}, \mathrm{Pb}, \mathrm{Mn}, \mathrm{Ni}, \mathrm{V}$, and $\mathrm{Zn}$ in fishes and shellfish from the Gulf of Catania. The results showed that the concentrations of $\mathrm{As}, \mathrm{Cd}, \mathrm{Cr}, \mathrm{Pb}, \mathrm{Mn}, \mathrm{Ni}, \mathrm{V}$, and $\mathrm{Zn}$ were $3.135-11.024 \mathrm{mg} / \mathrm{kg}, 0.0004-0.0013 \mathrm{mg} /$ $\mathrm{kg}, 0.007-0.015 \mathrm{mg} / \mathrm{kg}, 0.003-0.021 \mathrm{mg} / \mathrm{kg}, 0.122-2.454 \mathrm{mg} / \mathrm{kg}, 0.011-0.086 \mathrm{mg} / \mathrm{kg}$, $0.074-0.149 \mathrm{mg} / \mathrm{kg}$, and $3.418-6.580 \mathrm{mg} / \mathrm{kg}$ in fishes and $1.528 \mathrm{mg} / \mathrm{kg}, 0.0053 \mathrm{mg} / \mathrm{kg}$, $0.245 \mathrm{mg} / \mathrm{kg}, 0.071 \mathrm{mg} / \mathrm{kg}, 4.255 \mathrm{mg} / \mathrm{kg}, 0.327 \mathrm{mg} / \mathrm{kg}, 0.497 \mathrm{mg} / \mathrm{kg}$, and $7.625 \mathrm{mg} / \mathrm{kg}$ in shellfish, respectively [7]. The study combined the concentrations of heavy metals in aquatic products with the food intake of Italian adults and children to estimate the EDI of heavy metals in aquatic products and then compared the results with the human tolerable dose. The HQ value of heavy metals in all species was less than 1. Results indicated that (1) the consumption rates recommended to minimize risks to human health had been estimated, (2) the target hazard quotient values suggested that humans should minimize meals/week according to the species analyzed, (3) consuming fish with inorganic arsenic (iAs) concentrations was assumed to have an acceptable risk for cancer, and (4) the fishes and shellfish from the Gulf of Catania were safe to eat.

The assessment of potential human health risks is an important issue in the world. The traditional assessment depends on surveying the food chemicals of multiple foods based on a total diet study (TDS). TDS estimates the dietary exposures to food chemicals or nutrients and assesses health risks. It requires significant resources and funds to conduct detailed surveys and rigorous inspections. Hence, it is important to increase the value of assessments by constructing multiple decision trees to replace many kinds of inspection reports. This study designs and proposes heavy metal hazard decision trees for aquatic products, which are divided into seven categories including pelagic fishes, inshore fishes, other fishes, crustaceans, shellfish, cephalopods, and algae. This study collects 556 cooked fresh or processed seafood product samples. The constructions of the proposed heavy metal hazard decision trees include 12 heavy metals.

\section{Results}

This study constructs heavy metal hazard decision trees, including seven sub-heavy metal hazard decision trees, to estimate and describe the relationship between the seven categories of aquatic products and the long-term incorporation of iAs, Cd, Co, $\mathrm{Fe}, \mathrm{Sr}, \mathrm{Tl}$, and $\mathrm{Zn}$ heavy metals. The seven categories of aquatic products are pelagic fishes, inshore fishes, other fishes, crustaceans, shellfish, cephalopods, and algae. Aquatic products in this study are defined as those that people can easily buy at fish markets or supermarkets in counties or cities in Taiwan. The subjects are adults aged 19-64 years old [20-22]. The input dataset is total exposure, which is the category of aquatic products consumed from the databases of the Fishery Statistics Annual Report in Taiwan and the National Food Consumption Database in Taiwan [23, 24]. This study includes 2,529 cases of food intake. The heavy metal hazard decision tree has a two-stage construction. In the first stage, the heavy metal decision tree model is 
constructed by selecting and adjusting the factors based on 422 cases. In the second stage, the model evaluates cases and constructs rules. The 2,107 cases of eating 556 cooked fresh seafood or processed seafood product samples are used to determine rules. Table 1 presents the heavy metals of samples.

The principle behind the classification of aquatic products is to develop a representative list of fresh aquatic products roughly divided into seven categories based on Taiwan Food and Drug Administration (TFDA) announcements. The categories are (1) pelagic fishes, including shark, sailfish, tuna, and oil fish;

(2) inshore fishes, including cod, bonito, sea bream, catfish, anglerfish, flounder, mullet, stingray, hairtail, anchovy, scorpionfish, mullet, catfish, sturgeon, goldfish, eel, and barracuda; (3) other fishes, which are fishes other than pelagic fishes and inshore fishes; (4) cephalopods; (5) crustaceans; (6) algae; and (7) shellfish.

\section{Inorganic arsenic (iAs)}

The long-term intake of aquatic products with iAs may cause hyperpigmentation and keratosis follicularis in humans. The iAs Heavy Metal Hazard Decision Tree explains and describes the relationships between the seven categories of aquatic products and symptoms. The results of the estimation are shown in Fig. 1.

Figure 1 indicates that the intake of iAs in pelagic fishes, inshore fishes, other fishes, algae, and crustaceans will not easily cause hyperpigmentation and keratosis follicularis in adults. However, the intake of iAs in shellfish and cephalopods has the probability of causing hyperpigmentation and keratosis follicularis in adults.

(1) The intake of cephalopods. Among the 212 subjects whose body weights were less than or equal to $67.68(\mathrm{~kg}), 90$ subjects had HQ values greater than 1. For an adult whose body weight was less than or equal to $67.68(\mathrm{~kg})$ who ingested cephalopods with iAs, the risk of causing hyperpigmentation and keratosis follicularis was $42.5 \%$. In addition, among the 89 subjects whose body weights were greater than 67.68 (kg), 25 subjects had HQ values greater than 1 . For an adult whose body weight

Table 1 The heavy metals of samples (mean \pm standard deviation) $(\mathrm{mg} / \mathrm{kg}$ )

\begin{tabular}{|c|c|c|c|c|c|c|c|}
\hline Classification & Pelagic fishes & Inshore fishes & Other fishes & Crustaceans & Shellfish & Cephalopods & Algae \\
\hline $\begin{array}{l}\text { Number of } \\
\text { samples }\end{array}$ & 26 & 45 & 98 & 32 & 43 & 16 & 18 \\
\hline iAs & $0.0006 \pm 0.0011$ & $0.0023 \pm 0.0036$ & $0.0024 \pm 0.0036$ & $\quad 0.0027 \pm 0.0046$ & $0.025 \pm 0.0054$ & $0.0042 \pm 0.0096$ & $0.036 \pm 0.054$ \\
\hline $\mathrm{Cd}$ & $0.025 \pm 0.053$ & $0.0066 \pm 0.011$ & $0.0088 \pm 0.03$ & $0.10 \pm 0.16$ & $1.25 \pm 3.06$ & $0.43 \pm 0.78$ & $0.097 \pm 0.066$ \\
\hline Co & $0.003 \pm 0.002$ & $0.006 \pm 0.009$ & $0.0051 \pm 0.0049$ & $0.019 \pm 0.024$ & $0.19 \pm 0.31$ & $0.0067 \pm 0.0081$ & $0.024 \pm 0.024$ \\
\hline $\mathrm{Cr}$ & $0.10 \pm 0.16$ & $0.14 \pm 0.62$ & $0.063 \pm 0.11$ & $0.22 \pm 0.52$ & $0.16 \pm 0.23$ & $0.094 \pm 0.10$ & $0.20 \pm 0.18$ \\
\hline $\mathrm{Cu}$ & $1.23 \pm 1.61$ & $1.31 \pm 3.31$ & $2.97 \pm 8.01$ & $9.34 \pm 4.24$ & $6.98 \pm 8.80$ & $5.34 \pm 4.36$ & $2.61 \pm 3.44$ \\
\hline $\mathrm{Fe}$ & $5.15 \pm 4.06$ & $5.68 \pm 7.97$ & $6.17 \pm 8.90$ & $10.45 \pm 14.42$ & $71.46 \pm 67.25$ & $2.36 \pm 2.34$ & $39.84 \pm 52.52$ \\
\hline In & $0.0022 \pm 0.0073$ & $0.0026 \pm 0.0094$ & $0.0063 \pm 0.024$ & $0.0017 \pm 0.0037$ & $0.0025 \pm 0.0061$ & $0.0037 \pm 0.0066$ & $0.012 \pm 0.027$ \\
\hline $\mathrm{Mn}$ & $0.09 \pm 0.03$ & $0.16 \pm 0.22$ & $0.35 \pm 1.23$ & $0.83 \pm 0.86$ & $3.57 \pm 2.65$ & $0.20 \pm 0.14$ & $6.19 \pm 9.68$ \\
\hline $\mathrm{Ni}$ & $0.05 \pm 0.07$ & $0.079 \pm 0.29$ & $0.037 \pm 0.072$ & $0.15 \pm 0.27$ & $0.55 \pm 0.56$ & $0.055 \pm 0.066$ & $0.12 \pm 0.091$ \\
\hline $\mathrm{Pb}$ & $0.002 \pm 0.002$ & $0.0052 \pm 0.0056$ & $0.0079 \pm 0.014$ & $0.013 \pm 0.019$ & $0.082 \pm 0.071$ & $0.015 \pm 0.017$ & $0.13 \pm 0.11$ \\
\hline $\mathrm{Sr}$ & $0.27 \pm 0.16$ & $0.80 \pm 1.04$ & $2.47 \pm 9.12$ & $14.12 \pm 23.33$ & $6.29 \pm 3.59$ & $2.63 \pm 1.18$ & $20.90 \pm 21.47$ \\
\hline $\mathrm{Tl}$ & $0.0002 \pm 0.0002$ & $0.00037 \pm 0.00031$ & $0.00069 \pm 0.001$ & $0.00031 \pm 0.00026$ & $60.00074 \pm 0.00073$ & $\begin{array}{l}3 \\
3\end{array} 0.00020 \pm 0.00012$ & $0.00057 \pm 0.00050$ \\
\hline $\mathrm{Zn}$ & $4.78 \pm 1.45$ & $4.86 \pm 2.91$ & $6.49 \pm 7.23$ & $23.87 \pm 13.85$ & $36.50 \pm 34.14$ & $12.51 \pm 3.85$ & $3.88 \pm 3.43$ \\
\hline
\end{tabular}




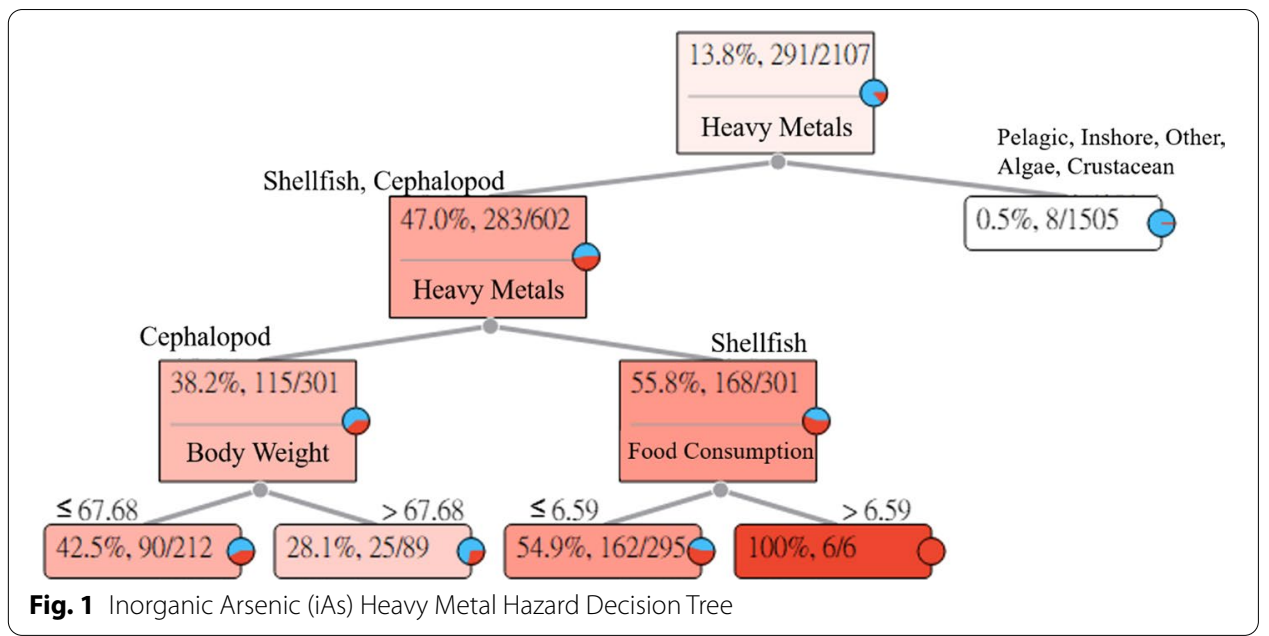

was greater than $67.68(\mathrm{~kg})$ who ingested cephalopods with iAs, the risk of causing hyperpigmentation and keratosis follicularis was $28.1 \%$.

(2) The intake of shellfish. Among the 295 subjects whose food intakes were less than or equal to 6.59 (g/week), 162 subjects had HQ values greater than 1. For an adult whose intake of shellfish with iAs was less than or equal to 6.59 (g/week), the risk of causing hyperpigmentation and keratosis follicularis was $54.9 \%$. In addition, among the six subjects whose food intakes were greater than 6.59 (g/week), six subjects had HQ values greater than 1 . For an adult whose intake of shellfish with iAs was greater than 6.59 (g/week), the risk of causing hyperpigmentation and keratosis follicularis was $100 \%$.

\section{Cadmium (Cd)}

The long-term intake of aquatic products with Cd may cause kidney diseases in humans. The Cd Heavy Metal Hazard Decision Tree explains and describes the relationships between the seven categories of aquatic products and symptoms. The results of the estimation are shown in Fig. 2.

Figure 2 indicates that the intake of $\mathrm{Cd}$ in pelagic fishes, inshore fishes, and other fishes will not easily cause kidney diseases in adults. However, the intake of $\mathrm{Cd}$ in shellfish, algae, cephalopods, and crustaceans has the probability of causing kidney diseases in adults.

(1) The intake of shellfish, algae, and cephalopods. Among the 212 subjects whose food intakes were less than or equal to 0.02 (g/week), 129 subjects had HQ values greater than 1. For an adult whose intake of shellfish, algae, and cephalopods with $\mathrm{Cd}$ was less than or equal to 0.02 (g/week), the risk of causing kidney diseases was $60.8 \%$. In addition, among the 691 subjects whose food intakes were greater than 0.02 (g/week), 475 subjects had HQ values greater than 1 . For an adult whose intake of shellfish, algae, and cephalopods with Cd was greater than 0.02 (g/week), the risk of causing kidney diseases was $68.7 \%$. 

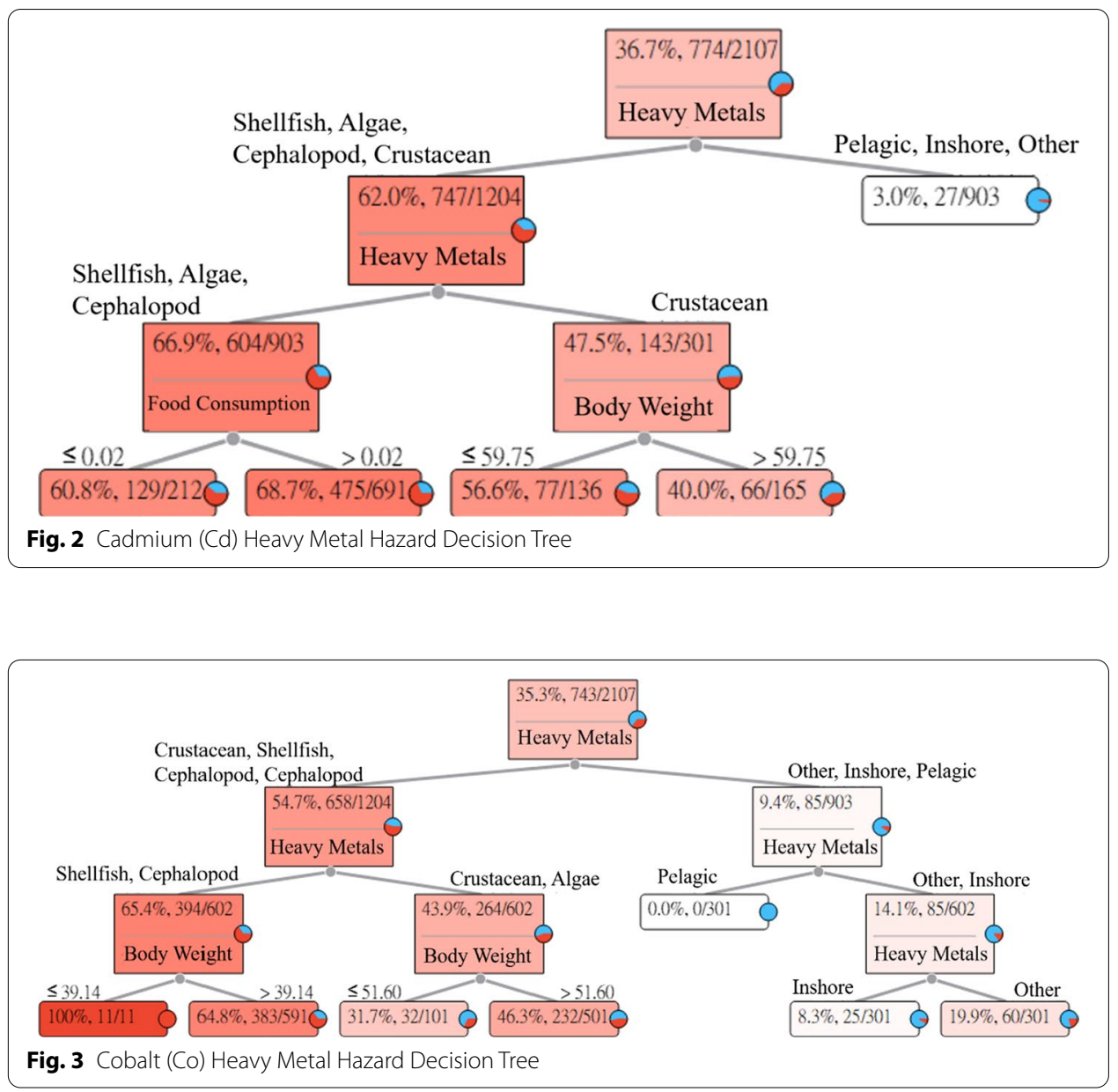

(2) The intake of crustaceans. Among the 136 subjects whose body weights were less than or equal to $59.75(\mathrm{~kg}), 77$ subjects had HQ values greater than 1 . For an adult whose body weight was less than or equal to $59.75(\mathrm{~kg})$ who ingested crustaceans with $\mathrm{Cd}$, the risk of causing kidney diseases was 56.6\%. In addition, among the 165 subjects whose body weights were greater than $59.75(\mathrm{~kg}), 66$ subjects had HQ values greater than 1 . For an adult whose body weight was greater than $59.75(\mathrm{~kg})$ who ingested crustaceans with $\mathrm{Cd}$, the risk of causing kidney diseases was $40.0 \%$.

\section{Cobalt (Co)}

The long-term intake of aquatic products with Co may cause goiter. The Co Heavy Metal Hazard Decision Tree explains and describes the relationships between the seven categories of aquatic products and symptoms. The results of the estimation are shown in Fig. 3.

Figure 3 indicates that the intake of Co in pelagic fishes, inshore fishes, and other fishes will not cause goiter in adults. However, the intake of Co in crustaceans, algae, shellfish, and cephalopods has the probability of causing goiter in adults.

(1) The intake of shellfish and cephalopods. Among the 11 subjects whose body weights were less than or equal to $39.14(\mathrm{~kg}), 11$ subjects had HQ values greater 
than 1. For an adult whose body weight was less than or equal to $39.14(\mathrm{~kg})$ who ingested shellfish and cephalopods with Co, the risk of causing goiter was $100 \%$. In addition, among the 591 subjects whose body weights were greater than $39.14(\mathrm{~kg})$, 383 subjects had HQ values greater than 1 . For an adult whose body weight was greater than $39.14(\mathrm{~kg})$ who ingested shellfish and cephalopods with Co, the risk of causing goiter was $64.8 \%$.

(2) The intake of crustaceans and algae. Among the 101 subjects whose body weights were less than or equal to $51.6(\mathrm{~kg}), 32$ subjects had HQ values greater than 1. For an adult whose body weight was less than or equal to $51.6(\mathrm{~kg})$ who ingested crustaceans and algae with Co, the risk of causing goiter was $31.7 \%$. In addition, among the 501 subjects whose body weights were greater than 51.6 (kg), 232 subjects had HQ values greater than 1 . For an adult whose body weight was greater than 51.6 $(\mathrm{kg})$ who ingested crustaceans and algae with Co, the risk of causing goiter was $46.3 \%$.

(3) The intake of pelagic fishes. None of the 301 subjects had HQ values greater than 1. For an adult who ingested pelagic fishes with Co, the risk of causing goiter was $0 \%$.

(4) The intake of inshore fishes. Among the 301 subjects, 25 subjects had HQ values greater than 1 . For an adult who ingested inshore fishes with Co, the risk of causing goiter was $8.3 \%$.

(5) The intake of other fishes. Among the 301 subjects, 60 subjects had HQ values greater than 1. For an adult who ingested other fishes with Co, the risk of causing goiter was $19.9 \%$.

\section{Iron (Fe)}

The long-term intake of Fe in aquatic products may cause gastrointestinal disorders. The Fe Heavy Metal Hazard Decision Tree explains and describes the relationships between the seven categories of aquatic products and symptoms. The results of the estimation are shown in Fig. 4.

Figure 4 indicates that the intake of $\mathrm{Fe}$ in crustaceans, algae, other fishes, inshore fishes, and pelagic fishes will not easily cause gastrointestinal disorders in adults.

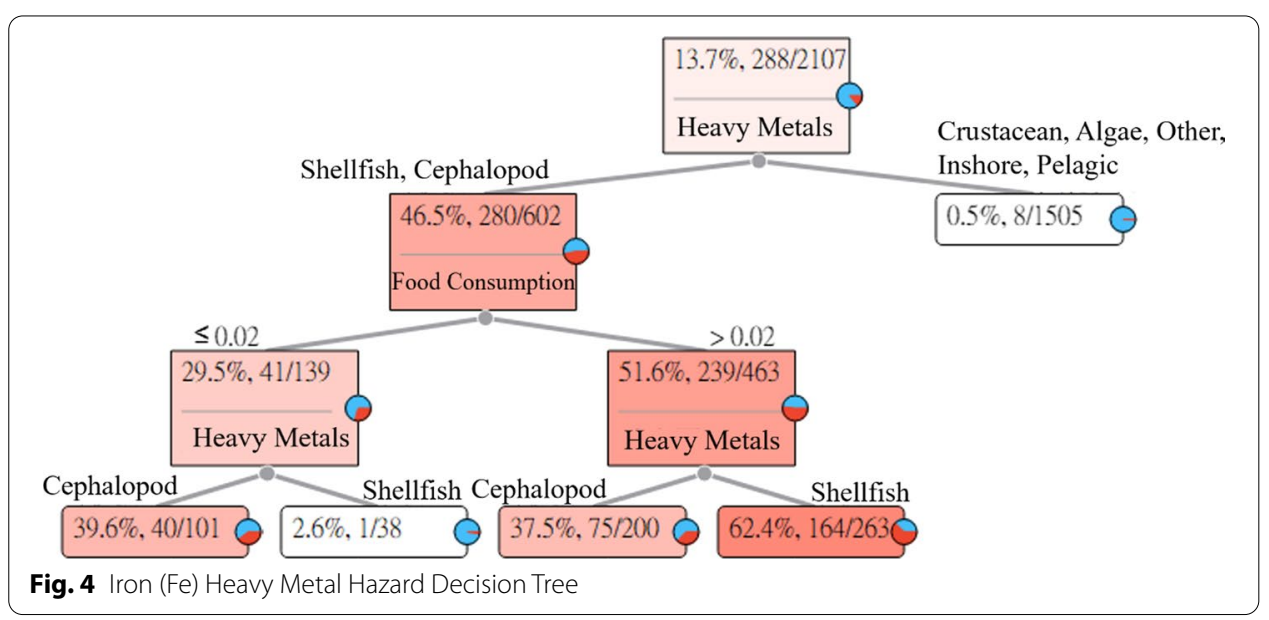


However, the intake of Fe in shellfish and cephalopods has the probability of causing gastrointestinal disorders in adults.

(1) The intake of shellfish and cephalopods with Fe that was less than or equal to 0.02 (g/week). Among the 101 subjects whose intake of cephalopods with Fe was less than or equal to 0.02 (g/week), 40 subjects had HQ values greater than 1 . For an adult who ingested cephalopods with Fe, the risk of causing gastrointestinal disorders was $39.6 \%$. In addition, among the 38 subjects whose intake of shellfish with $\mathrm{Fe}$ was less than or equal to 0.02 (g/week), one subject had HQ values greater than 1. For an adult who ingested shellfish with Fe, the risk of causing gastrointestinal disorders was $2.6 \%$.

(2) The intake of shellfish and cephalopods with Fe that was greater than 0.02 (g/week). Among the 200 subjects whose intake of cephalopods with Fe was greater than 0.02 (g/week), 75 subjects had $\mathrm{HQ}$ values greater than 1. For an adult who ingested cephalopods with Fe, the risk of causing gastrointestinal disorders was $37.5 \%$. In addition, among the 263 subjects whose intake of shellfish with Fe was greater than 0.02 (g/week), 164 subjects had HQ values greater than 1 . For an adult who ingested shellfish with Fe, the risk of causing gastrointestinal disorders was $62.4 \%$.

\section{Strontium (Sr)}

The long-term intake of $\mathrm{Sr}$ in aquatic products may cause adult rickets. The Sr Heavy Metal Hazard Decision Tree explains and describes the relationships between the seven categories of aquatic products and symptoms. The results of the estimation are shown in Fig. 5.

Figure 5 indicates that the intake of $\mathrm{Sr}$ in algae, other fishes, shellfish, inshore fishes, and pelagic fishes will not easily cause rickets in adults. However, the intake of $\mathrm{Sr}$ in crustaceans and cephalopods has the probability of causing rickets in adults.

(1) The intake of cephalopods. Among the 42 subjects whose body weights were less than or equal to $50.07(\mathrm{~kg}), 32$ subjects had HQ values greater than 1. For an adult

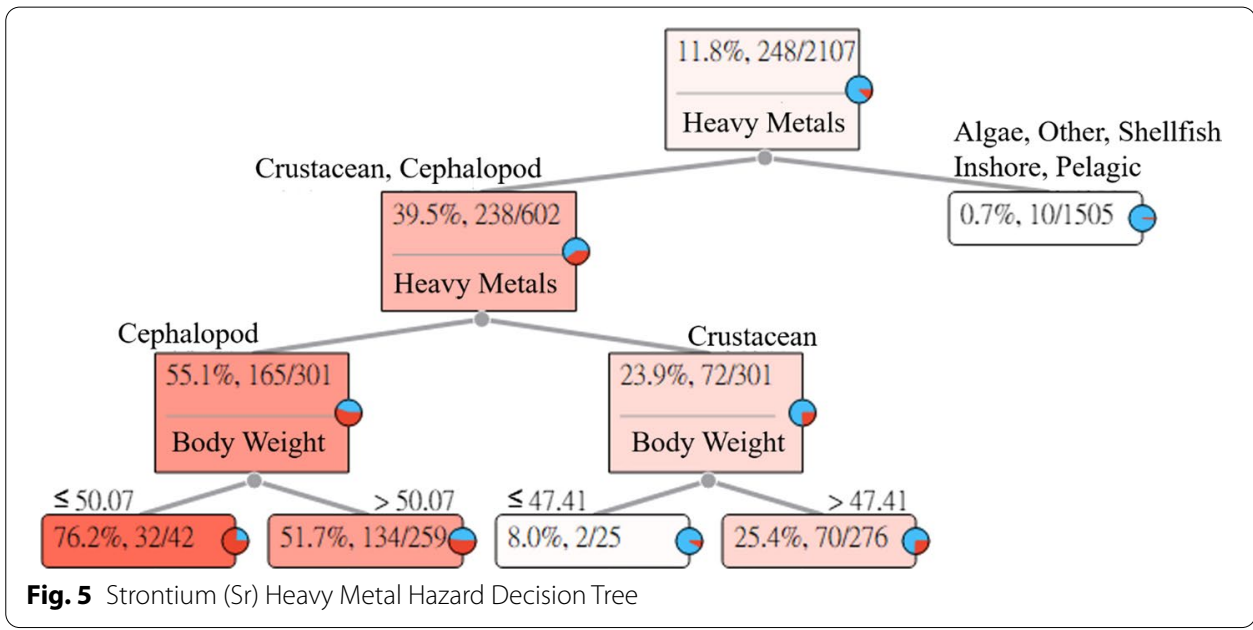


whose body weight was less than or equal to $50.07(\mathrm{~kg})$ who ingested cephalopods with $\mathrm{Sr}$, the risk of causing adult rickets was $76.2 \%$. In addition, among the $259 \mathrm{sub}$ jects whose body weights were greater than $50.07(\mathrm{~kg}), 134$ subjects had HQ values greater than 1. For an adult whose body weight was greater than $50.07(\mathrm{~kg})$ who ingested cephalopods with $\mathrm{Sr}$, the risk of causing adult rickets was $51.7 \%$.

(2) The intake of crustaceans. Among the 25 subjects whose body weights were less than or equal to $47.41(\mathrm{~kg})$, two subjects had HQ values greater than 1 . For an adult whose body weight was less than or equal to $47.41(\mathrm{~kg})$ who ingested crustaceans with Sr, the risk of causing adult rickets was $8.0 \%$. In addition, among the 276 subjects whose body weights were greater than $47.41(\mathrm{~kg}), 70$ subjects had HQ values greater than 1. For an adult whose body weight was greater than $47.41(\mathrm{~kg})$ who ingested crustaceans with $\mathrm{Sr}$, the risk of causing adult rickets was $25.4 \%$.

\section{Thallium (TI)}

The long-term intake of $\mathrm{Tl}$ in aquatic products may cause perifollicular atrophy. The $\mathrm{Tl}$ Heavy Metal Hazard Decision Tree explains and describes the relationships between the seven categories of aquatic products and symptoms. The results of the estimation are shown in Fig. 6.

Figure 6 indicates that the probability of the intake of $\mathrm{Tl}$ in pelagic fishes, inshore fishes, and other fishes causing perifollicular atrophy in adults is about $9.2 \%$, while the probability of the intake of $\mathrm{Tl}$ in crustaceans, shellfish, cephalopods, and algae causing perifollicular atrophy in adults is about $47.8 \%$.

(1) The intake of shellfish and cephalopods. Among the 322 subjects whose body weights were less than or equal to $61.15(\mathrm{~kg}), 166$ subjects had HQ values greater than 1. For an adult whose body weight was less than or equal to $61.15(\mathrm{~kg})$ who ingested shellfish and cephalopods with $\mathrm{Tl}$, the risk of causing perifollicular atrophy was $51.6 \%$. In addition, among the 280 subjects whose body weights were greater than $61.15(\mathrm{~kg}), 183$ subjects had HQ values greater than 1 . For an adult whose body weight was greater than $61.15(\mathrm{~kg})$ who ingested shellfish and cephalopods with $\mathrm{Tl}$, the risk of causing perifollicular atrophy was $65.4 \%$.

(2) The intake of crustaceans and algae. None of the six subjects whose body weights were less than or equal to $36.47(\mathrm{~kg})$ had HQ values greater than 1. For an adult

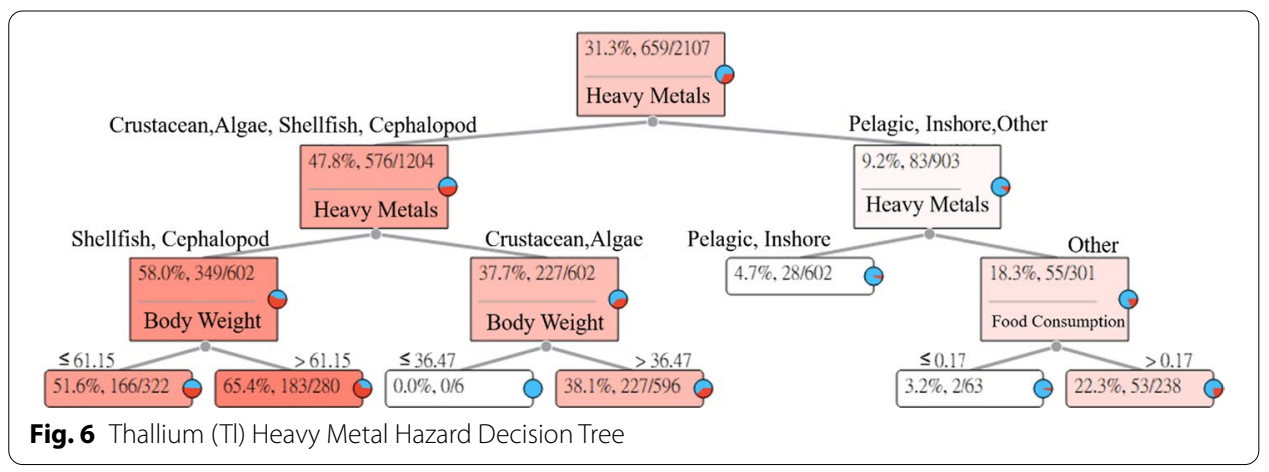


whose body weight was less than or equal to $36.47(\mathrm{~kg})$ who ingested crustaceans and algae with $\mathrm{Tl}$, the risk of causing perifollicular atrophy was $0 \%$. In addition, among the 596 subjects whose body weights were greater than $36.47(\mathrm{~kg}), 227 \mathrm{sub}-$ jects had HQ values greater than 1. For an adult whose body weight was greater than $36.47(\mathrm{~kg})$ who ingested crustaceans and algae with $\mathrm{Tl}$, the risk of causing perifollicular atrophy was $38.1 \%$.

(3) The intake of pelagic fishes and inshore fishes. Among the 602 people, 28 subjects had HQ values greater than 1 . For an adult who ingested pelagic fishes and inshore fishes with $\mathrm{Tl}$, the risk of causing perifollicular atrophy was $4.7 \%$.

(4) The intake of other fishes. Among the 63 subjects whose food intakes were less than or equal to 0.17 (g/week), two subjects had HQ values greater than 1 . For an adult whose intake of other fishes with $\mathrm{Tl}$ was less than or equal to 0.17 (g/week), the risk of causing perifollicular atrophy was $3.2 \%$. In addition, among the 238 subjects whose food intakes were greater than 0.17 (g/week), 53 subjects had HQ values greater than 1. For an adult whose intake of other fishes with $\mathrm{Tl}$ was greater than 0.17 (g/week), the risk of causing perifollicular atrophy was $22.3 \%$.

\section{Zinc (Zn)}

The long-term intake of $\mathrm{Zn}$ in aquatic products may reduce superoxide dismutase activity in red blood cells. The Zn Heavy Metal Hazard Decision Tree explains and describes the relationships between the seven categories of aquatic products and symptoms. The results of the estimation are shown in Fig. 7.

Figure 7 indicates that the probability of the intake of $\mathrm{Zn}$ in pelagic fishes, inshore fishes, other fishes, and cephalopod reducing superoxide dismutase activity in red blood cells in adults is about $26.2 \%$, while the probability of the intake of $\mathrm{Zn}$ in crustaceans, shellfish, and algae reducing superoxide dismutase activity in red blood cells in adults is about $57.5 \%$.

(1) The intake of other fishes and cephalopods. None of the six subjects whose body weights were less than or equal to $86.92(\mathrm{~kg})$ had HQ values greater than 1 . For an adult whose body weight was less than or equal to $86.92(\mathrm{~kg})$ who ingested other fishes and cephalopods with $\mathrm{Zn}$, the risk of reducing superoxide dismutase activity in red blood cells was $0 \%$. In addition, among the 596 subjects whose body weights were greater than $86.92(\mathrm{~kg}), 189$ subjects had HQ values greater than 1 . For an adult whose body weight

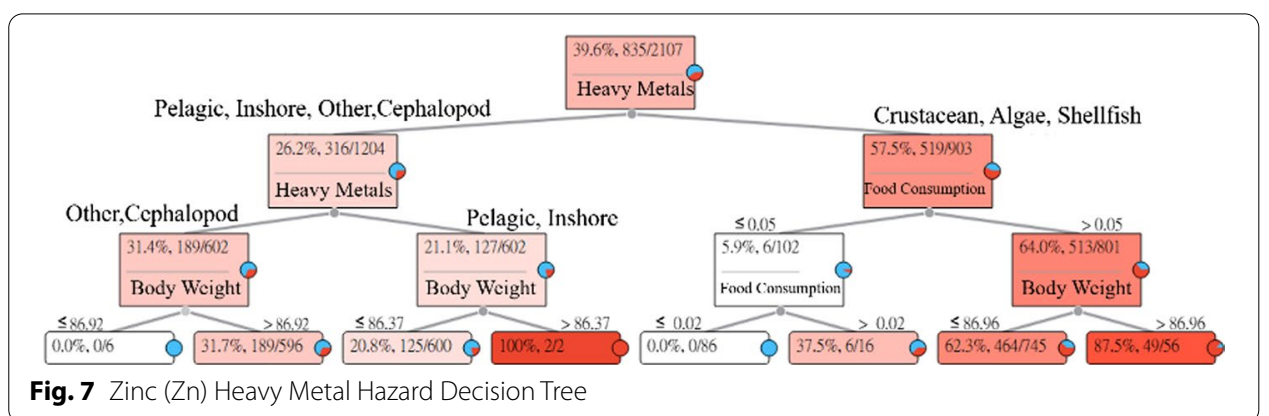


was greater than $86.92(\mathrm{~kg})$ who ingested other fishes and cephalopods with $\mathrm{Zn}$, the risk of reducing superoxide dismutase activity in red blood cells was $31.7 \%$.

(2) The intake of pelagic fishes and inshore fishes. Among the 600 subjects whose body weights were less than or equal to $86.37(\mathrm{~kg}), 125$ subjects had HQ values greater than 1. For an adult whose body weight was less than or equal to $86.37(\mathrm{~kg})$ who ingested pelagic fishes and inshore fishes with $\mathrm{Zn}$, the risk of reducing superoxide dismutase activity in red blood cells was $20.8 \%$. In addition, among the two subjects whose body weights were greater than $86.37(\mathrm{~kg})$, both had HQ values greater than 1. For an adult whose body weight was greater than $86.37(\mathrm{~kg})$ who ingested pelagic fishes and inshore fishes with $\mathrm{Zn}$, the risk of reducing superoxide dismutase activity in red blood cells was $100 \%$.

(3) The intake of crustaceans, algae, and shellfish. None of the 86 subjects whose food intakes were less than or equal to 0.02 (g/week) had HQ values greater than 1 . For an adult whose intake of crustaceans, algae, and shellfish with $\mathrm{Zn}$ was less than or equal to 0.02 ( $\mathrm{g} /$ week), the risk of reducing superoxide dismutase activity in red blood cells was $0 \%$. In addition, among the 16 subjects whose food intakes were greater than 0.02 (g/week), six subjects had HQ values greater than 1. For an adult whose intake of crustaceans, algae, and shellfish with $\mathrm{Zn}$ was greater than $0.02 \mathrm{~g} /$ week), the risk of reducing superoxide dismutase activity in red blood cells was $37.5 \%$.

(4) The intake of crustaceans, algae, and shellfish. Among the 745 subjects whose body weights were less than or equal to $86.96(\mathrm{~kg}), 464$ subjects had HQ values greater than 1. For an adult whose body weight was less than or equal to $86.96(\mathrm{~kg})$ who ingested crustaceans, algae, and shellfish with $\mathrm{Zn}$, the risk of reducing superoxide dismutase activity in red blood cells was $62.3 \%$. In addition, among the 56 subjects whose body weights were greater than $86.96(\mathrm{~kg}), 49$ subjects had HQ values greater than 1. For an adult whose body weight was greater than $86.96(\mathrm{~kg})$ who ingested crustaceans, algae, and shellfish with $\mathrm{Zn}$, the risk of reducing superoxide dismutase activity in red blood cells was $87.5 \%$.

\section{Discussion}

Risk assessment includes hazard identification, dose-response assessment, exposure assessment, and risk characterization. After the $\mathrm{Cr}, \mathrm{Cu}, \mathrm{Mn}, \mathrm{Ni}$, and $\mathrm{Pb}$ values are calculated using the HQ, it is found that they will not cause adverse effects on the human body. Hence, this study focuses on explaining and constructing the heavy metal hazard decision trees of iAs, $\mathrm{Cd}, \mathrm{Co}, \mathrm{Fe}, \mathrm{Sr}, \mathrm{Tl}$, and $\mathrm{Zn}$. The proposed heavy metal hazard decision trees illustrate multiple suggestions and related hazards concerning the intake of aquatic products with iAs, $\mathrm{Cd}, \mathrm{Co}, \mathrm{Fe}, \mathrm{Sr}, \mathrm{Tl}$, and $\mathrm{Zn}$ in Taiwan. The analyzed highest risks are described as follows.

(1) For an adult whose intake of shellfish with iAs is greater than 6.59 (g/week), the risk of causing hyperpigmentation and keratosis follicularis is $100 \%$. 
(2) For an adult whose intake of shellfish, algae, and cephalopod with $\mathrm{Cd}$ is greater than 0.02 (g/week), the risk of causing kidney disease is $68.7 \%$.

(3) For an adult whose body weight is less than or equal to $39.14 \mathrm{~kg}$ who ingests shellfish and cephalopod with Co, the risk of causing goiter is $100 \%$.

(4) For an adult whose intake of shellfish with Fe is greater than 0.02 (g/week), the risk of causing gastrointestinal disorders is $62.4 \%$.

(5) For an adult whose body weight is less than or equal to $50.07 \mathrm{~kg}$ who ingests cephalopods with Sr, the risk of causing adult rickets is $76.2 \%$.

(6) For an adult whose body weight is greater than $61.15 \mathrm{~kg}$ who ingests shellfish and cephalopods with $\mathrm{Tl}$, the risk of causing perifollicular atrophy is $65.4 \%$.

(7) For an adult whose body weight is greater than $86.37 \mathrm{~kg}$ who ingests pelagic fishes and inshore fishes with $\mathrm{Zn}$, the risk of reducing superoxide dismutase activity in red blood cells is $100 \%$.

Therefore, it is recommended that people should eat aquatic products appropriately, pay attention to their heavy metal content, and avoid the excessive intake of heavy metals.

\section{Conclusions}

The health problems resulting from different heavy metals in the body vary according to the different types of metals, exposure time, and exposure dose. This study designs and proposes heavy metal hazard decision trees for aquatic products, which are divided into seven categories including pelagic fishes, inshore fishes, other fishes, crustaceans, shellfish, cephalopods, and algae. Based on these classifications, representative fresh and processed seafood products are at the root of the heavy metal hazard decision trees. The study discusses 12 kinds of heavy metals, which are iAs, Cd, $\mathrm{Co}, \mathrm{Cr}, \mathrm{Cu}, \mathrm{Fe}, \mathrm{Mn}, \mathrm{Ni}, \mathrm{Pb}, \mathrm{Sr}, \mathrm{Tl}$, and $\mathrm{Zn}$. After the $\mathrm{Cr}, \mathrm{Cu}, \mathrm{Mn}, \mathrm{Ni}$, and $\mathrm{Pb}$ values are calculated using the $\mathrm{HQ}$, it is found that they will not cause adverse effects on the human body. Hence, this study focuses on explaining and constructing the heavy metal hazard decision trees of iAs, $\mathrm{Cd}, \mathrm{Co}, \mathrm{Fe}, \mathrm{Sr}, \mathrm{Tl}$, and $\mathrm{Zn}$. Finally, five research recommendations are proposed for researchers.

(1) To design and develop a deep learning mechanism for the risk assessment of aquatic products. It can make the assessment results more accurate and predictable.

(2) To study the interactive influence model of diversified diets. Different diet patterns could have different risk assessments.

(3) To study the relationships between individual and group risk assessments. This analysis could identify high-risk groups and their eating habits.

(4) To study the relationships among environmental pollutions, heavy metal poisons, and fishing conditions based on the fluctuations and differences in the contained heavy metals. The changes and trends can be used to obtain more accurate estimates of the dietary risks and safety of aquatic products. 
(5) To survey the conditions of different aquatic products within different sea areas in Taiwan. This analysis could help consumers to know the food safety of aquatic products in a specific sea area.

\section{Methods}

A decision tree is a kind of a predictive model for classification and prediction in machine learning. It represents a mapping relationship between the object attributes and the object values [25-27]. Each node in the tree represents an object, and each path represents a possible attribute value. Each leaf node corresponds to the value of the object represented by the path from the root to the leaf node. Decision tree is a frequently used technique in data mining, which can be used to analyze data and make predictions [28-31]. The processes of constructing the heavy metal hazard decision trees are illustrated in Fig. 8.

The input dataset is total exposure, which is the category of aquatic products consumed from the databases of the Fishery Statistics Annual Report in Taiwan and the National Food Consumption Database in Taiwan, combined with the aquatic product sampling method. After sampling, homogenization, and cooking, the concentrations of heavy metals in various aquatic products are measured. Formula (1) calculates the food intake to estimate the EDI of heavy metals in the aquatic products ingested by each exposed group [5].

$$
\mathrm{EDI}_{\mathrm{ij}}=\sum_{\mathrm{j}=1}^{\mathrm{n}} \frac{\mathrm{C}_{\mathrm{i}} \times \mathrm{CR}_{\mathrm{ij}} \times 10^{-3}}{\mathrm{BW}_{\mathrm{j}}}
$$

$E D I_{i j}$ is the average daily estimated intake of heavy metals in the aquatic product, $i$, ingested by each exposed group, $j$ ( $\mathrm{mg} / \mathrm{kg}$ bw/day). $C_{i}$ is the concentration of heavy metals in the cooked aquatic product, $I(\mathrm{mg} / \mathrm{kg}) . C R_{i j}$ is the food intake of the aquatic

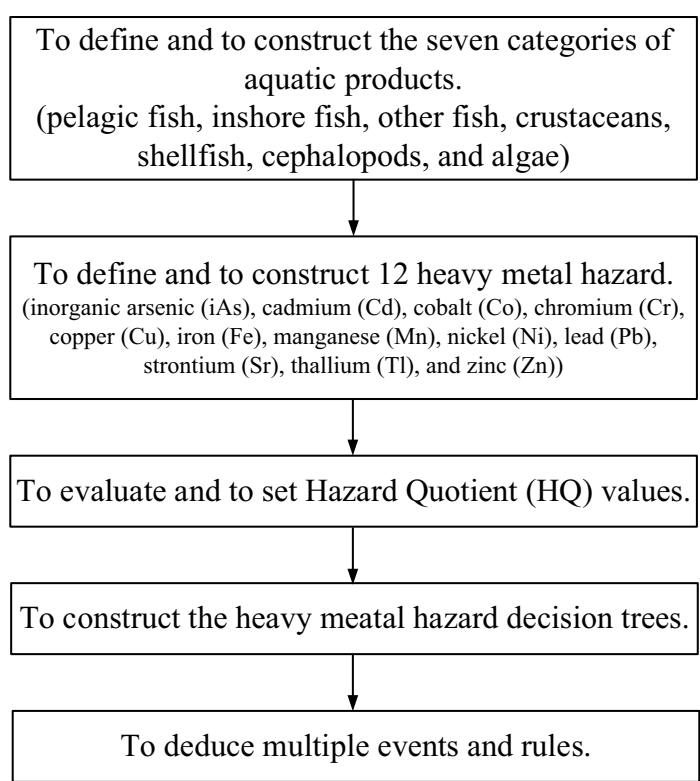

Fig. 8 The processes of constructing the heavy metal hazard decision trees 
product, $i$, ingested by each exposed group, $j$ (consumption rate, g/day). $B W_{j}$ is the body weight of each exposed group, $j(\mathrm{~kg})$.

Based on these classifications, representative fresh and processed seafood products are at the root of the heavy metal hazard decision trees. For the specific exposure, the Hazard Quotient (HQ) is obtained by comparing the EDI and the reference dose of the hazardous substance, which also represents the ratio of the toxic substance dose to the tolerable dose ingested by the consumer through the same route for a long time. When the HQ value is less than or equal to 1 , it means that the health risk caused by the intake of a heavy metal is within an acceptable range. If the HQ value is greater than 1 , it means that the intake of a heavy metal is in excess and may have adverse effects on the consumer's health. There is a risk of poisoning or illness $[11,12]$. The formula for the HQ is denoted as Formula (2).

$$
H Q_{i j}=\frac{E D I_{i j}}{H B G V}
$$

$H Q_{i j}$ is the $\mathrm{HQ}$ of heavy metals in the aquatic products, $i$, ingested by each exposed group, $j . E D I_{i j}$ is the estimated average daily intake of heavy metals in the aquatic product, $i$, of each exposure group, $j$ ( $\mathrm{mg} / \mathrm{kg}$ bw/day). HBGV is the abbreviation of HealthBased Guidance Value. Hence, HQ can be denoted as Formula (3):

$$
H Q_{i j}=\frac{C_{i} \times C R_{i j}}{B W_{j} \times R f D_{i}}
$$

$C_{i}$ is the concentration of heavy metals in the cooked aquatic product, $i(\mathrm{mg} / \mathrm{kg}) . C R_{i j}$ is the intake of aquatic product, $i$, in each exposed group, $j$ (consumption rate, g/day). $B W_{j}$ is the body weight of each exposed group, $j(\mathrm{~kg}) . R f D$ is the abbreviation of Reference Dose, which is $\mathrm{mg} / \mathrm{kg}$ bw/day.

This study designs and proposes heavy metal hazard decision trees for aquatic products, which are divided into seven categories including pelagic fishes, inshore fishes, other fishes, crustaceans, shellfish, cephalopods, and algae. The heavy metal hazard decision trees are based on the HQ to assess the potential health risks of human exposure to heavy metals through the ingestion of aquatic products. The subjects are adults aged 19-64 years old [20-22]. The heavy metals examined are iAs, $\mathrm{Cd}, \mathrm{Co}, \mathrm{Cr}, \mathrm{Cu}, \mathrm{Fe}, \mathrm{Mn}, \mathrm{Ni}$, $\mathrm{Pb}, \mathrm{Sr}, \mathrm{Tl}$, and $\mathrm{Zn}$. After the $\mathrm{Cr}, \mathrm{Cu}, \mathrm{Mn}, \mathrm{Ni}$, and $\mathrm{Pb}$ values are calculated using the $\mathrm{HQ}$, it is found that they will not cause adverse effects on the human body. Hence, this study explains and constructs the heavy metal hazard decision trees of iAs, $\mathrm{Cd}, \mathrm{Co}, \mathrm{Fe}, \mathrm{Sr}, \mathrm{Tl}$, and $\mathrm{Zn}$. Table 2 illustrates the algorithm of the proposed heavy metal hazard decision trees.

Information Gain, Gain(S, A), is the response for selecting an attribute to be a node of the decision tree. When the Gain $(S, A)$ value is larger, the messiness of the data is smaller. This attribute is more suitable as a node. Split Information, $\operatorname{SplitInfo}_{A}(S)$, is the entropy of the distribution of instances into branches. Gain Ratio, GainRatio(A), reduces its bias attributes. It takes the number and size of branches into account when choosing, which corrects the value by the Information Gain and the Split Information. It makes the decision tree model more accurate. Formulas (4), (5), and (6) illustrate the construction of the heavy metal hazard decision trees. 
Table 2 The algorithm of the heavy metal hazard decision tree

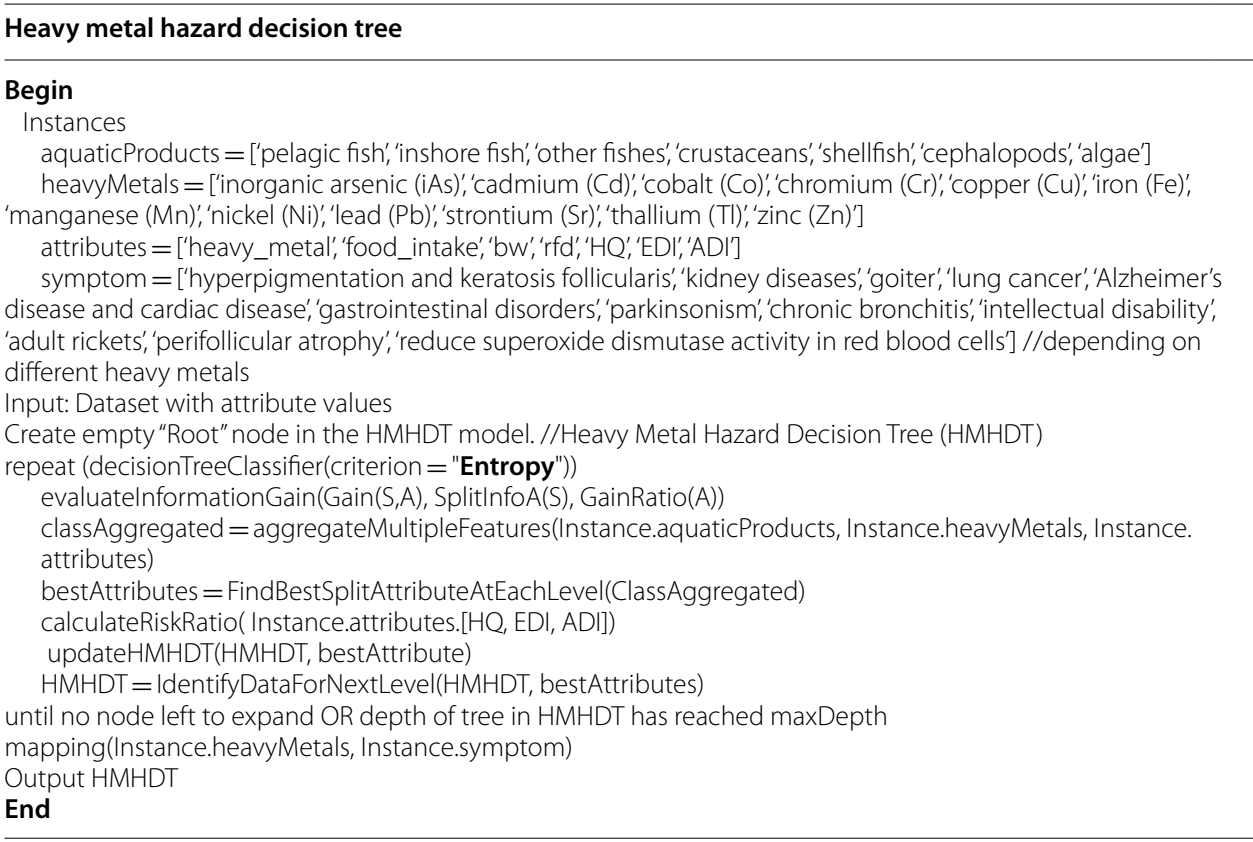

$$
\begin{aligned}
& \operatorname{Gain}(S, A)=\operatorname{Entropy}(S)-\sum_{j=1}^{v} \frac{\left|S_{j}\right|}{|S|} \operatorname{Entropy}\left(S_{j}\right) \\
& \operatorname{SplitInfo}_{A}(S)=-\sum_{j=1}^{v} \frac{\left|S_{j}\right|}{|S|} \times \log _{2}\left(\frac{S_{j}}{S}\right)
\end{aligned}
$$

$$
\operatorname{GainRatio}(A)=\operatorname{Gain}(\mathrm{S}, \mathrm{A}) / \operatorname{SplitInfo}_{A}(\mathrm{~S})
$$

$\operatorname{Entropy}(S)$ is dataset $S . v$ is the different sub-data collections. $\frac{\left|S_{j}\right|}{|S|}$ is the ratio of the number of data in the $j$ th sub-collection to the total data collections.

\section{Abbreviations}

iAs: Inorganic arsenic; Cd: Cadmium; Co: Cobalt; Cr: Chromium; Cu: Copper; Fe: Iron; Mn: Manganese; Ni: Nickel; Pb: Lead; Sr: Strontium; TI: Thallium; Zn: Zinc; V: Vanadium; HQ: Hazard quotient; USEPA: United States Environmental Protection Agency; EDI: Estimated daily intake; ADI: Acceptable daily intake; PTWI: Provisional tolerable weekly intake; BMDL: Benchmark dose lower confidence limit; MRL: Maximum residue limit; TDS: Total diet study; RfD: Reference dose; TFDA: Taiwan Food and Drug Administration.

\section{Acknowledgements}

The Ministry of Science and Technology of the R.O.C. under the grant MOST 109-2221-E-019-033 and MOST 108-2221-E019-046 -MY2 support this research.

\section{About this supplement}

This article has been published as part of BMC Bioinformatics Volume 22 Supplement 5 2021: Proceedings of the International Conference on Biomedical Engineering Innovation (ICBEI) 2019-2020. The full contents of the supplement are available at https://bmcbioinformatics.biomedcentral.com/articles/supplements/volume-22-supplement-5.

\section{Authors' contributions}

The authors confirm contribution to the paper as follows: Conceptualization, P.P. and M.P.; Methodology, H.H.; Software, H.H.; Validation, P.P., H.H. and M.P.; Formal Analysis, M.P.; Investigation, P.P. and M.P.; Resources, P.P. and M.P.; Data Curation, M.P.; Writing-Original Draft Preparation, H.H. and M.P.; Writing-Review \& Editing, H.H.; Visualization, H.H.; Supervision, M.P.; Project Administration, H.H. and M.P.; Funding Acquisition, H.H. and M.P. All authors read and approved the final manuscript. 


\section{Funding}

This study was supported by the Ministry of Science and Technology of Taiwan (MOST 109-2221-E-019-033 and MOST 108-2221-E-019-046-MY2) and National Health Research Institutes, Taiwan (NHRI-EM-110-GP-01 and NHRI-106A1PDCO-2917172). Publication costs are funded by MOST 108-2221-E-019-046-MY2. The funders do not play any roles in the design of the study, the collection, analysis, and interpretation of data, and the writing of this manuscript.

\section{Availability of data and materials}

The datasets generated from open access databases are available in the "Fishery Statistics Annual Report" repository, https://www.fa.gov.tw/cht/PublicationsFishYear/ and "National Food Consumption Database" repository, http://tnfcds. cmu.edu.tw/index.php?action=download\&p=6. The datasets are analyzed by the proposed method of this study.

\section{Declarations}

Ethics approval and consent to participate

Not applicable.

\section{Consent for publication}

Not applicable.

\section{Competing interests}

The authors declare that they have no competing interests.

\section{Author details}

${ }^{1}$ Institute of Food Safety and Risk Management, National Taiwan Ocean University, Keelung City 20224, Taiwan. ${ }^{2}$ Department of Food Science, National Taiwan Ocean University, Keelung City 20224, Taiwan. ${ }^{3}$ National Institute of Environmental Health Sciences, National Health Research Institutes, Zhunan Town, Miaoli County 35053, Taiwan.

Received: 11 January 2022 Accepted: 19 January 2022

Published online: 17 February 2022

\section{References}

1. Ju YR, Chen CW, Chen CF, Chuang XY, Dong CD. Assessment of heavy metals in aquatic fishes collected from southwest coast of Taiwan and human consumption risk. Int Biodeterior Biodegrad. 2017;124:314-25.

2. Cui B, Zhan Q, Zhang K, Liu X, Zhang H. Analyzing trophic transfer of heavy metals for food webs in the newlyformed wetlands of the Yellow River1 Delta, China. Environ Pollut. 2011;159:1297-306.

3. Lin Y, Yu X, Huang L, Sanganyado E, Bi R, Li P, Liu W. Risk assessment of potentially toxic elements accumulated in fish to Indo-Pacific humpback dolphins in the South China Sea. Sci Total Environ. 2020;761:143256.

4. Ahmed MK, Baki MA, Isla MS, Kundu GK, Habibullah-Al-Mamun M, Sarkar SK, Hossain MM. Human health risk assessment of heavy metals in tropical fish and shellfish collected from the River Buriganga, Bangladesh. Environ Sci Pollut Res. 2015;22:15880-90.

5. Ling MP, Hsu HT, Shie RH, Wu CC, Hong YS. Health risk of consuming heavy metals in farmed tilapia in central Taiwan. Bull Environ Contam Toxicol. 2009;83:558-64.

6. Morais S, Costa FG, Pereira ML. Heavy metals and human health. In: Environmental Health-Emerging Issues and Practice. IntechOpen. 2012.

7. Copat C, Arena G, Fiore M, Ledd C, Fallico R, Sciacca S, Ferrante M. Heavy metals concentrations in fish and shellfish from Eastern Mediterranean Sea: consumption advisories. Food Chem Toxicol. 2013;53:33-7.

8. Duran A, Tuzen M, Soylak M. Assessment of trace metal concentrations in muscle tissue of certain commercially available fish species from Kayseri. Turkey Environ Monit Assess. 2014;186:4619-28.

9. Cui D, Zhang P, Li H, Zhang Z, Song Y, Yang Z. The dynamic changes of arsenic biotransformation and bioaccumulation in muscle of freshwater food fish crucian carp during chronic dietborne exposure. J Environ Sci. 2021;100:74-81.

10. Dasgupta S, Mustafa G, Paul T, Wheeler D. The socioeconomics of fish consumption and child health: an observational cohort study from Bangladesh. World Dev. 2020;137:105201.

11. USEPA (United States Environmental Protection Agency). Provisional Peer-Reviewed Toxicity Values for Iron and Compounds. Washington, DC, EPA/690/R-06/020F, 2006.

12. USEPA (United States Environmental Protection Agency). US Environmental Protection Agency Region III Risk Based Concentration Table: Technical Background Information. 2006

13. Sroy S, Arnaud E, Servent A, In S, Avallone S. Nutritional benefits and heavy metal contents of freshwater fish species from Tonle Sap Lake with SAIN and LIM nutritional score. J Food Compos Anal. 2020;96:103731.

14. Carlos SC, Manuel SM, Roberth PU, José MN, Sergi D. Dataset of concentrations of mercury and methylmercury in fish from a Tropical River impacted by gold mining in the Colombian Pacific. Data Brief. 2020;33(2):128478.

15. Resma NS, Meaze AMH, Hossain S, Khandaker MU, Kamal M, Deb N. The presence of toxic metals in popular farmed fish species and estimation of health risks through their consumption. Physic Open. 2020;5:100052.

16. Sergio FT, Jhon JLP, María JM, Rosa CRMD, Mateo R. Metals and metalloids in freshwater fish from the floodplain of Tablas de Daimiel National Park, Spain. . Ecotox Environ Safe. 2021;208:111602.

17. Olmedo P, Pla A, Hernández AF, Barbier F, Ayouni L, Gil F. Determination of toxic elements (mercury, cadmium, lead, tin and arsenic) in fish and shellfish samples. risk assessment for the consumers. Environ Int. 2013:59:63-72.

18. Qin D, Jiang H, Bai S, Tang S, Mou Z. Determination of 28 trace elements in three farmed cyprinid fish species from northeast China. Food Control. 2015:50:1-8. 
19. Santos LFP, Trigueiro INS, Lemos VA, Nóbrega Furtunato DM, Cardoso RDCV. Assessment of cadmium and lead in commercially important seafood from São Francisco do Conde, Bahia. Brazil Food Control. 2013;33:193-9.

20. National Food Consumption Database. Taiwan Food and Drug Administration \& National Health Research Institutes. 2021. https://tnfcds.nhri.edu.tw/index.php?action=search_list. Accessed 15 Sep 2021.

21. USDA ERS - Food Consumption and Nutrient Intakes. US Economic Research Service. 2021, https://www.ers.usda. gov/data-products/food-consumption-and-nutrient-intakes. Accessed 15 Sep 2021.

22. European Food Safety Authority. Use of the EFSA comprehensive european food consumption database in exposure assessment. EFSA J. 2011;9(3):2097.

23. Fishery Statistics Annual Report repository. Taiwan Fisheries Agency. 2018. https://www.fa.gov.tw/cht/Publicatio nsFishYear/content.aspx?id=33\&chk=6aa2c133-d15a-4a21-87b5-810a91929b84. Accessed 15 Sep 2021.

24. National Food Consumption Database repository. Taiwan Food and Drug Administration \& National Health Research Institutes. 2018. http://tnfcds.cmu.edu.tw/index.php?action=download\&p=6. Accessed 15 Sep 2021.

25. Lee JS. AUC4.5: AUC-based C4.5 decision tree algorithm for imbalanced data classification. IEEE Access. 2019;7:106034-42.

26. Salzberg SL. C4.5: programs for machine learning by J. Ross Quinlan. Morgan Kaufmann Publishers, Inc., 1993. In Machine Learning. 1994;16:235-40.

27. Wirawan IM, Widiyaningtyas T, Siti NB, Nutritional status of infants classification by calculating anthropometry through C4.5 algorithm. In: Proceedings of 2019 Electrical, Electronics and Information Engineering;2019, pp. 216-9.

28. Haider W, Rehman AU, Durrani NM, Rehman SU. A generic approach for wheat disease classification and verification using expert opinion for knowledge-based decisions. IEEE Access. 2021;9:31104-29.

29. Kuang YC, Streeter L, Cree MJ, Ooi MPL. Evaluation of deep neural network and alternating decision tree for Kiwifruit detection. In: Proceedings of the 2019 IEEE International Instrumentation and Measurement Technology Conference; 2019, pp. 1-6.

30. Ren A, Zahid A, Zoha A, Shah SA, Imran MA, Alomainy A, Abbasi QH. Machine learning driven approach towards the quality assessment of fresh fruits using non-invasive sensing. IEEE Sens J. 2020;20(4):2075-83.

31. Wajid A, Singh NK, Junjun P, Mughal MA. Recognition of ripe, unripe and scaled condition of orange citrus based on decision tree classification. In: Proceedings of the 2018 International Conference on Computing, Mathematics and Engineering Technologies; 2018, pp. 1-4.

\section{Publisher's Note}

Springer Nature remains neutral with regard to jurisdictional claims in published maps and institutional affiliations.

- fast, convenient online submission

- thorough peer review by experienced researchers in your field

- rapid publication on acceptance

- support for research data, including large and complex data types

- gold Open Access which fosters wider collaboration and increased citations

- maximum visibility for your research: over 100M website views per year

At BMC, research is always in progress.

Learn more biomedcentral.com/submissions 